\title{
Prevalence of Gestational Diabetes Mellitus in Overweight Pregnant Women in Urban Antenatal Clinic at 24-28 Weeks of Gestation
}

\author{
Rinku Joshi', Rosy Malla ${ }^{2}$,Madhur Dev Bhattarai ${ }^{3}$ and Dhan Bahadur Shrestha ${ }^{4}$
}

1: Department of Medicine, Nepalese Army Institute of Health Sciences, Shree Birendra Hospital, Chhauni, Kathmandu, Nepal.

2: Department of Obstetrics and Gynaecology, Nepalese Army Institute of Health Sciences, Shree Birendra Hospital, Chhauni, Kathmandu, Nepal.

3: Department of Medicine; National Academy of Medical Sciences, Bir Hospital, Kathmandu, Nepal.

4: Nepalese Army Institute of Health Sciences, Shree Birendra Hospital, Chhauni, Kathmandu, Nepal.

\begin{abstract}
Introduction: Diabetes has become a significant health problem all over the world and its prevalence is increasing rapidly. Prevalence of gestational diabetes mellitus (GDM) is directly related to the prevalence of type 2 diabetes. Women who are overweight or obese before pregnancy are more at risk of GDM irrespective of other factors.

Methods: This was a hospital based cross-sectional prospective study conducted among the women attending antepartum clinic, in a tertiary level hospital of Lalitpur for one-year. All overweight (prepregnancy body mass index; BMI >23) women at $24-28$ weeks of gestation were enrolled. Fasting blood glucose, screening $50 \mathrm{gm}$ oral glucose challenge test (OGTT) and 2 hour OGTT following overnight fasting was done and GDM was diagnosed based on standard guidelines.

Results: Out of 256 women, majority had BMI $>25 \mathrm{~kg} / \mathrm{m}^{2}(\mathrm{n}=180), 59 \%$ were multiparous and $41 \%$ were primiparas. Positive screening test was obtained in 51 women (19.9\%). The incidence of GDM by ADA and WHO criteria was $10(3.9 \%)$ and $16(6.3 \%)$ respectively. There was statistically nonsignificant difference in the rate of positive screening test and BMI $(\mathrm{p}=0.09)$. The abnormal screening test between primiparous and multiparous was significant $(\mathrm{p}=0.01)$.

Conclusion: This study showed a high pre-pregnancy BMI and the incidence of GDM. However, the difference is not statistically significant The rate of positive screening test is also higher than the previous studies.

Keywords: gestational diabetes; overweight; pregnancy; Nepal
\end{abstract}

Correspondence: Rinku Joshi, Department of Medicine, Nepalese Army Institute of Health Sciences, Shree Birendra Hospital, Chhauni, Kathmandu, Nepal. Email: drrinkujoshi@gmail.com

To cite this article: Joshi R, Malla R, Bhattarai MD, Shrestha DB. Prevalence of Gestational Diabetes Mellitus in Overweight Pregnant Women in Urban Antenatal Clinic at 24-28 Weeks of Gestation. Medical Journal of Shree Birendra Hospital. 2017;17(2):55-62.

DOI: $\underline{\text { http://dx.doi.org/10.3126/mjsbh.v16i2.17854 }}$

Conflict of Interest: None declared 


\section{INTRODUCTION}

Diabetes Mellitus is a group of metabolic disorders probably because of changing lifestyles leading to hyperglycemia. ${ }^{1}$ Its prevalence is increasing rapidly throughout the globe more so in developing nations creating socioeconomic and medical burden. ${ }^{2}$

In one study from Nepal, Diabetes and impaired fasting glucose were present in $14.6 \%$ and $9.1 \%$ respectively of the people $>20$ years in urban and $2.5 \%$ and $1.3 \%$ in the rural areas. ${ }^{3}$ Gestational diabetes mellitus is defined as glucose intolerance of various degrees that is first detected during pregnancy. ${ }^{4}$ The prevalence of GDM may range from $1 \%$ to $14 \%$ of all pregnancies, based on the population and diagnostic tests employed. 5

The International Diabetes Foundation (IDF) says that, "Diabetes and Obesity are the biggest public health challenge of the 21 st century". 6 The mechanism of causal association between obesity and GDM appears to be related to the endocrine milieu associated with obesity. Data suggest that obese women should be encouraged to undertake a weight reduction program prior to conceiving. ${ }^{7-9}$ Asians due to a higher percentage of body fat have high risk of diabetes and cardiovascular disease at BMIs lower than the existing WHO International cutoff point for overweight (>24.9kg/m2). ${ }^{9,10} \mathrm{GDM}$ is associated with adverse pregnancy outcomes. ${ }^{11}$

Study from Nepalese women $(n=300)$ showed $3.67 \%$ of pregnancies had positive screening test

\begin{tabular}{|l|c|}
\hline $\begin{array}{l}\text { Table 1: WHO Categorization of BMI based } \\
\text { on recommendation for Asia-Pacific region. }\end{array}$ \\
\hline Categories & BMI $(\mathrm{kg} / \mathrm{m} 2)$ \\
\hline Underweight & $<18.5$ \\
\hline Normal weight & $18.5-22.9$ \\
\hline Overweight at risk & $23-24.9$ \\
\hline Obese I & $25-29.9$ \\
\hline Obese II & $\geq 30$ \\
\hline
\end{tabular}

value and $0.66 \%$ was diagnosed as having GDM in 24-28 weeks of gestation. 12 There are very few studies done on obesity and overweight with its association to GDM in the urban population of Nepal. Hence we intended to study the correlation pf obesity and GDM in Nepalese urban population.

\section{METHODS}

This was a hospital based prospective study conducted at ante partum clinic of a tertiary center for a duration of 12 months from $1^{\text {st }}$ of June 2008 to $31^{\text {st }}$ of May 2009. Pregnant women of 24-38 weeks of gestation with pre-pregnancy BMI $23 \mathrm{~kg} / \mathrm{m}^{2}$ from urban residency were included while pregnancy with connective tissue diseases, endocrine diseases, asthma and chronic liver disease; pre-pregnancy diabetes, hypertension under medication were excluded.

Data were collected using pre-tested questionnaire on the routine ante-natal days. At initial visit, a

Table 2: 1999 WHO Diabetes criteria- Interpretation of Oral Glucose Tolerance Test

\begin{tabular}{|l|c|c|c|c|c|c|c|c|}
\hline \multicolumn{2}{|c|}{ Glucose levels } & \multicolumn{2}{|c}{ Normal } & \multicolumn{2}{c}{$\begin{array}{c}\text { Impaired fasting } \\
\text { glycaemia (IFG) }\end{array}$} & $\begin{array}{c}\text { Impaired glucose } \\
\text { tolerance (IGT) }\end{array}$ & $\begin{array}{c}\text { Diabetes Mellitus } \\
\text { (DM) }\end{array}$ \\
\hline Venous Plasma & Fasting & $2 \mathrm{hrs}$ & Fasting & $2 \mathrm{hrs}$ & Fasting & $2 \mathrm{hrs}$ & Fasting & $2 \mathrm{hrs}$ \\
\hline $\mathrm{mmol} / \mathrm{L}$ & $<6.1$ & $<7.8$ & $>6.1 \&<7.0$ & $<7.8$ & $<7.0$ & $>7.8$ & $>7.0$ & $>11.1$ \\
\hline $\mathrm{mg} / \mathrm{dL}$ & $<100$ & $<140$ & $>100 \&<126$ & $<140$ & $<126$ & $>140$ & $>126$ & $>200$ \\
\hline
\end{tabular}


Table 3: American Diabetes Association (ADA) Criteria for 2 hours, 75 grams GDM

\begin{tabular}{|l|r|r|r|}
\hline $\begin{array}{l}\text { Glucose } \\
\text { levels }\end{array}$ & Fasting & One Hour & Two Hour \\
\hline $\mathrm{mmol} / \mathrm{L}$ & 5.3 & 10.0 & 8.6 \\
\hline $\mathrm{mg} / \mathrm{Dl}$ & 95 & 180 & 155 \\
\hline
\end{tabular}

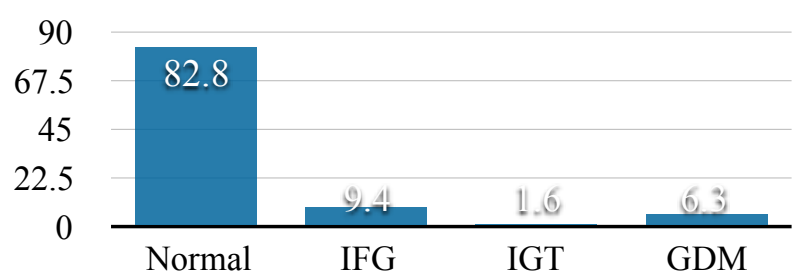

Figure 1: Percentage of women having IFG, IGT and GDM according to WHO criteria

thorough history was taken including a demographic profile, social history, past medical and obstetric history including risk factors for gestational diabetes mellitus and dietary habits. Physical and obstetrical examination were carried out and all women were counseled about the study.

Pre-pregnancy BMI was calculated by two ways; in the pregnant women with the known pre-pregnancy weight, BMI was calculated by weight- to height ratio $\left(\mathrm{kg} / \mathrm{m}^{2}\right)$ and in those with no known prepregnancy weight, BMI was calculated by subtracting the measured weight by expected weight gain in normal pregnancy. It was assumed that up to 20 weeks of gestation, gain of total $3 \mathrm{~kg}$ and subsequently, $0.5 \mathrm{~kg} /$ week with an average of 10-13 kgs of weight gain during pregnancy.
All the enrolled women underwent initial nonchallenge glucose test (i.e. fasting blood glucose).Those with the fasting plasma glucose level $>126 \mathrm{mg} / \mathrm{dl}(7 \mathrm{mmol} / \mathrm{L})$, confirmed by rechecking, were directly included in the study. If the plasma level was lower than the given value they further needed screening $50-\mathrm{g}$ oral glucose challenge test. The screening value of $\geq 130 \mathrm{mg} / \mathrm{dl}$ was considered positive. Women with positive test underwent 2-hr oral glucose challenge test (OGTT) following overnight fasting. Gestational Diabetes was diagnosed in women if there are two or more abnormal values of OGTT according to ADA gestational diabetes criteria and one or more abnormal values according to WHO.

The diagnosed GDM cases were managed further with the conjoined efforts of gynecologist and physician either by dietary management or by insulin therapy depending upon blood glucose levels. Ethical clearance was obtained by local IRC for the thesis conduction. Informed written consent was taken from the eligible candidates of the study. Obtained data was entered and analysed using MS excel 2007 and SPSS 17 version with the help of statistician. After analyzing the data by Chi square, Z-test and Fisher's exact test, the results were expressed.

\section{RESULTS}

Total 256 consecutive women with BMI $\geq 23 \mathrm{~kg} /$ $\mathrm{m}^{2}$ were included in the study. Among them, 51 $(19.9 \%)$ women had abnormal screening test, 6

Table 4: Result of screening test value according to maternal age

\begin{tabular}{|l|c|c|c|}
\hline \multicolumn{1}{|c|}{ Age in Years } & \multicolumn{3}{|c|}{ Screening test } \\
\hline & Negative & Positive & \\
\hline$\leq 30$ years & $48(90.6 \%)$ & $5(9.4 \%)$ & $53(100 \%)$ \\
\hline$>30$ years & $157(77.3 \%)$ & $46(22.7 \%)$ & $203(100 \%)$ \\
\hline Total & $205(80.1 \%)$ & $51(19.9 \%)$ & $256(100 \%)$ \\
\hline
\end{tabular}


Table 5: Result of screening test value according to maternal BMI

\begin{tabular}{|c|c|c|c|}
\hline \multicolumn{1}{|c|}{ BMI $(\mathrm{Kg} / \mathrm{m} 2)$} & \multicolumn{3}{|c|}{ Screening test } \\
\hline & Negative & Positive & Total \\
\hline $\mathbf{2 3}-\mathbf{2 4 . 9}$ & $56(73.7 \%)$ & $20(26.3 \%)$ & $160(100 \%)$ \\
\hline $\mathbf{2 5}$ & $149(82.8 \%)$ & $31(17.2 \%)$ & $256(100 \%)$ \\
\hline
\end{tabular}

Table 6: Result of OGTT (WHO) according to BMI

\begin{tabular}{|c|c|c|c|c|c|}
\hline \hline BMII(Kg/m2) & \multicolumn{7}{|c|}{ OGTT(WHO) } \\
\hline & Normal & IFG & IGT & GDM & Total \\
\hline $\mathbf{2 3}-\mathbf{2 4 . 9 9}$ & 64 & 7 & 2 & 3 & 76 \\
\hline$>\mathbf{2 5}$ & 148 & 17 & 2 & 13 & 180 \\
\hline Total & 212 & 24 & 4 & 16 & 256 \\
\hline
\end{tabular}

women had positive non-challenge blood sugar test and 45 women had abnormal 50 gm glucose challenge test. So, these women underwent $75 \mathrm{gm}$ OGTT test. Among these 51 women; 10 (19.6\%) and $16(31.3 \%)$ women had GDM according to ADA and WHO criteria respectively. The minimum and maximum values after 1-hour GCT were 134 $\mathrm{mg} / \mathrm{dL}$ and $313 \mathrm{mg} / \mathrm{dL}$ respectively.

Among the women studied, majority belonged to the Newar community $(41.4 \%)$ followed by Brahmin (20.3\%), Chhetri (17.2\%) and Mongoloids (15.6\%) and rest $5.5 \%$ were other caste. Majority of women $(180,70.31 \%)$ included in the study were of BMI $\geq 25 \mathrm{~kg} / \mathrm{m}^{2}$, rest $(76,29.68 \%)$ of the women were of BMI between 23 to $24.99 \mathrm{~kg} / \mathrm{m}^{2}$.

There was significant difference $(\mathrm{p}=0.03)$ in the positive value of GCT among those with age $>30$ years and those with age less than or equal to 30 years.

No statistically significant variation $(\mathrm{p}=0.09)$ was observed in screening test values between women with BMI $\geq 25 \mathrm{~kg} / \mathrm{m}^{2}$, and those with BMI between
$23-24.99 \mathrm{~kg} / \mathrm{m}^{2}$. Nearly two third $(59 \%)$ women were multiparous and rest of the women were primiparous. Most of the women $(64,68.81 \%)$ who had abnormal screening were multiparous while, 29 $(31.18 \%)$ were primiparous. The parity and abnormal screening test were significant $(p=0.01$ ).

Among the overall women studied who had abnormal GCT, 10 (3.9\%) women turned out to be positive for OGTT according to ADA criteria.

Among 256 women in 212 (82.8\%) 75 gm OGTT according to WHO criteria turned to be normal. IFG in $24(9.4 \%)$, IGT in $4(1.6 \%)$ and GDM in 16 $(6.3 \%)$ women with total 44 women with abnormal OGTT in our study.

Among 180 women with $\mathrm{BMI} \geq 25 \mathrm{~kg} / \mathrm{m}^{2}, 13$ women had positive OGTT and among 76 women who had BMI between 23-24.99 kg/m², 3 women had positive OGTT meeting WHO criteria. However, the difference was not statistically significant $(p$-value $=0.71)$.

Among 180 women with BMI $\geq 25 \mathrm{~kg} / \mathrm{m}^{2}, 7$ had positive OGTT and among 76 women who had 
Table 7: Result of OGTT (ADA) according to BMI

\begin{tabular}{|c|c|c|c|}
\hline BMI (kg/m2) & \multicolumn{3}{|c|}{ OGTT(ADA) } \\
\hline & Negative & Positive & Total \\
\hline $\mathbf{2 3 - 2 4 . 9 9}$ & 73 & 3 & 76 \\
\hline$>25$ & 173 & 7 & 180 \\
\hline Total & 246 & 10 & 256 \\
\hline
\end{tabular}

Table 8: Comparison of women with WHO and ADA-OGTT

\begin{tabular}{|c|c|c|c|}
\hline WHO-OGTT & \multicolumn{3}{|c|}{ ADA-OGTT result } \\
\hline & Normal & Abnormal & Total \\
\hline Normal & 210 & 2 & 212 \\
\hline IFG & 24 & 0 & 24 \\
\hline IGT & 3 & 1 & 4 \\
\hline GDM & 9 & 7 & 16 \\
\hline Total & 246 & 10 & 256 \\
\hline
\end{tabular}

BMI between $23-24.99 \mathrm{~kg} / \mathrm{m}^{2}, 3$ had positive OGTT based on ADA criteria.

Among 44 women who were found to have abnormal OGTT according to WHO criteria, only 10 women were found to have abnormal OGTT values when ADA values were considered.

\section{DISCUSSION}

Diabetes has become a public health concern of the present time worldwide, including in Nepal and the prevalence is increasing rapidly. There is increasing evidence that diabetes mellitus will be one of the foremost public health challenges to face in the near future. With increasing obesity, decreasing physical activity and rising life expectancy of population, prevalence of diabetes is increasing. There are some distinctive features reported in relation to diabetes in Nepal. In one study done in
Nepal from January 1999 to December 2003, Diabetes and IFG were present in $14.6 \%$ and $9.1 \%$ respectively of the people $\geq 20$ years in urban and $2.5 \%$ and $1.3 \%$ in the rural areas ${ }^{13}$. The prevalence of diabetes has been found to be $14.6 \%$ among the people $\geq 20$ years and $19 \%$ among $\geq 40$ years and in urban Nepal. In rural areas, the prevalence of diabetes was $2.5 \%$ among the people $\geq 20$ years and $3.3 \%$ among $\geq 40$ years 3 .

The babies born to mothers with GDM are reported to have upto $45 \%$ risk of developing diabetes, compared with $8.6 \%$ in babies of mothers who develop diabetes after pregnancy or $1.4 \%$ in babies of mothers without diabetes. As the women of childbearing age start having glucose intolerance, either due to rise in prevalence or increased weight or age of women at the time of pregnancy, a vicious cycle of increased risk of diabetes leading to accelerated rise of prevalence may occur. There are numerous contributory factors which play a role in the development of GDM e.g. maternal age, prepregnancy BMI, glucose intolerance etc. which increase the risk of maternal hyperglycemia and its effect in the offspring.

GDM is common problem in pregnancy these days which may be asymptomatic, yet produce fetal morbidity and even mortality. GDM detection is important because appropriate therapy can decrease fetal and maternal morbidity and mortality, particularly due to macrosomia. ${ }^{14}$ The frequency of GDM usually reflects the frequency of type 2 diabetes in the underlying population. There is a unique problem of excessive weight gain by women due to over-eating after delivery in urban areas in Nepal. Traditionally, after delivery - or even after abortion- women in Nepal are often prevented from engaging in any activities, including travelling, other than almost continuously eating calorie- rich foods that are high in fat content. 
In one study, the average weight gain in six months after delivery was $15.9 \mathrm{~kg}$ from the basal value; the body mass index increased from $21.3 \pm 1.8$ before pregnancy to $27.9 \pm 2.5$ six months after delivery. 15 The recommended life style measures for prevention of DM and GDM and its complications are to increase the physical activities and to adopt healthy diet, particularly avoiding oily and fatty foods. The ACOG acknowledges that universal screening is the most sensitive and more practical approach; they also state that screening may be omitted in low risk women. One study found that if only high-risk women are screened, approximately $35 \%$ of GDM will not be discovered. 16 The study done in Canada showed that pregnant women who had a plasma glucose level about $7.2 \mathrm{mmol} / \mathrm{L}$ (130 $\mathrm{mg} / \mathrm{dL}$ ) but a normal GTT revealed higher risk of macrosomia than those with a level below this. ${ }^{17}$

The present study was conducted on 256 overweight (pre-pregnancy $\mathrm{BMI} \geq 23$ ) urban women in their 24-28 weeks of gestation for the study of prevalence of GDM among them. If their fasting glucose levels were found to be $<126 \mathrm{mg} \%$, 50 -g GCT was performed. Out of 256 women, positive screening test, including both positive fasting result and positive glucose challenge test was obtained in 51 women $(19.9 \%)$. The overall incidence of GDM by ADA and WHO criteria was $10(3.9 \%)$ and $16(6.3 \%)$ respectively. However, the rate of positivity of GDM among those with positive screening values according to ADA and WHO criteria were $19.6 \%$ and $31.3 \%$ respectively.
More women were diagnosed as having GDM when WHO criteria was applied as only 2 values of ADA criteria was taken into in this study. Though the overall percentage of GDM was $6.3 \%$, considerable percentage of women belonged to the groups of IFG (17.2\%) and IGT (3.1\%), who should be given special attention as they are at subsequent risk for developing overt diabetes. They should try to achieve their ideal bodyweight through diet and exercise and, if possible, they should avoid drugs that may adversely affect glucose tolerance (e.g., glucocorticoids).

There is not much information regarding GDM among Nepalese women, which may be due to financial and logistic constrains. The present study emphasizes the importance of keeping prepregnancy weight optimum to avoid even subclinical hyperglycemia, for prevention and control of GDM. To achieve the challenging measures, the world resources need to be mobilized involving International agencies, like World Health Organization and others.

\section{CONCLUSIONS}

This study showed a high pre-pregnancy BMI and the incidence of GDM. The rate of positive screening test is also higher than the previous studies pointing GDM is a growing issue and must be well addressed. However, since our study is a single centric study, it is recommended that our findings should be substantiated with more larger, multi-centric studies in the future.

\section{REFERENCES}

1. Powers AC. Diabetes Mellitus. In: Fauci AS, Kasper DL, Longo DL, Braunwald E, Hauser SL, Jameson JL eds. Harrison's principles of Internal Medicine . 17th edition. New York. 2008; 2275-2310. 
2. Bhattarai MD. Three patterns of rising type 2 diabetes prevalence in the world: need to widen the concept of prevention in individuals into control in the community. Journal of Nepal Medical Association. 2009 Apr 1;48(174):173-9.

3. Singh DL, Bhattarai MD. High prevalence of diabetes and impaired fasting glycaemia in urban Nepal. Diabetic Medicine.2003;20:170-1.

DOI: https://doi.org/10.1046/j.1464-5491.2003.00829 4.x

4. Buchanan TA, Xiang AH. Gestational diabetes mellitus. J Clin Invest. 2005; 115(3):485-91.

DOI: https://doi.org/10.1172/JCI200524531

5. Gajjar F, Maitra NK. Intrapartum and perinatal outcomes in women with Gestational diabetes and mild gestational hyperglycemia. Obstet Gynecol India. 2005; 55(2) 135-137.

6. Ernst MC, Issa M, Goralski, K. B, Sinal C. J.Chemerin Exacerbates Glucose Intolerance in Mouse Models of Obesity and Diabetes. Endocrinology. 2010;151: 1998-2007.

DOI: https://doi.org/10.1210/en.2009-1098PMid:20228173

7. Obesity and reproduction: an educational bulletin. FertilSteril 2008; 90:S21.

DOI: https://doi.org/10.1016/j.fertnstert.2008.08.005PMid:19007633

8. Moos MK, Dunlop AL, Jack BW, Nelson L, Coonrod DV, Long R et. al. Healthier women, healthier reproductive outcomes: recommendations for the routine care of all women of reproductive age. Am $\mathrm{J}$ Obstet Gynecol 2008; 199:S280.

DOI: https://doi.org/10.1016/j.ajog.2008.08.060PMid:19081422

9. WHO Expert Consultation. Appropriate body-mass index for Asian populations and its implications for policy and intervention strategies. Lancet. 2004; 363:157-63.

DOI: https://doi.org/10.1016/S0140-6736(03)15268-3

10. WHO, International Association for the Study of Obesity, International Obesity Task Force. The Asia Pacific perspective: Redefining obesity and its treatment. Health Communications. Sydney, 2000.

11. Jindal A, Ahmed F, Bhardwaj B, Chaturvedi B. Prevalence, clinical profile and outcome of gestational diabetes mellitus. J. of Obst. Gyn. of India.2001; 51(4): 46-49.

12. Rana A, Pradhan N, Gurung G, Singh M. Screening test for gestational diabetes. Journal of institute of medicine.1998; 20: 193-197.

13. Singh DL, Bhattarai MD. Prevalence of diabetes and profile of diabetic patients in Nepal. Post-Graduate Medical Journal of Nepal. 2004; 5(1):7-12.

14. Riskin-Mashiah S, Younes G, Damti A, Auslender R. First-trimester fasting hyperglycemia and adverse pregnancy outcomes. Diabetes Care 2009; 32:1639.

DOI: https://doi.org/10.2337/dc09-0688PMid:19549728 PMCid:PMC2732138 
15. Bhattarai MD, Singh DL. Excessive weight gain after pregnancy in urban areas: one important area to prevent diabetes. Nepal Med Coll J. 2005 Dec; 7(2):87-9. PMid:16519070

16. Hillier TA, Vesco KK, Pedula KL, Beil TL, Whitlock EP, Pettitt DJ. Screening for gestational diabetes mellitus: a systematic review for the U.S. Preventive Services Task Force. Ann Intern Med. 2008; 148:766.

DOI: https://doi.org/10.7326/0003-4819-148-10-200805200-00009PMid:18490689

17. Canadian Task Force on the Periodic Health Examination. Periodic health examination, 1992 update: 1. Screening for gestational diabetes mellitus. Canadian medical Association Journal 1992; 147:436-43. 